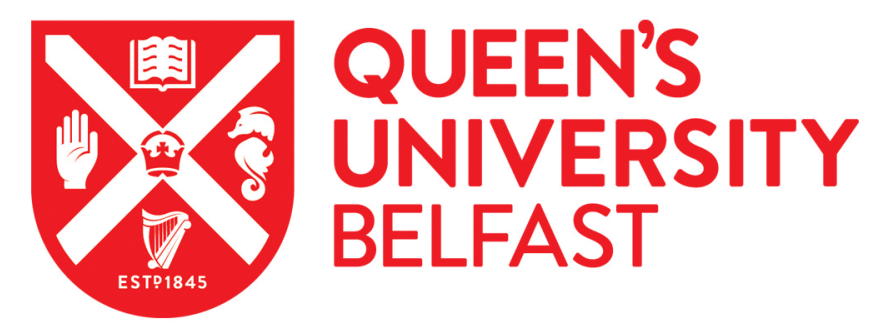

\title{
The multiple origins of sexual size dimorphism in global amphibians
}

Pincheira-Donoso, D., Harvey, L. P., Grattarola, F., Jara, M., Cotter, S. C., Tregenza, T., \& Hodgson, D. J. (2021). The multiple origins of sexual size dimorphism in global amphibians. Global Ecology \& Biogeography, 30(2), 443. https://doi.org/10.1111/geb.13230

\section{Published in:}

Global Ecology \& Biogeography

\section{Document Version:}

Peer reviewed version

Queen's University Belfast - Research Portal:

Link to publication record in Queen's University Belfast Research Portal

\section{Publisher rights}

Copyright 2020, The Publisher

This work is made available online in accordance with the publisher's policies. Please refer to any applicable terms of use of the publisher

\section{General rights}

Copyright for the publications made accessible via the Queen's University Belfast Research Portal is retained by the author(s) and / or other copyright owners and it is a condition of accessing these publications that users recognise and abide by the legal requirements associated with these rights.

Take down policy

The Research Portal is Queen's institutional repository that provides access to Queen's research output. Every effort has been made to ensure that content in the Research Portal does not infringe any person's rights, or applicable UK laws. If you discover content in the Research Portal that you believe breaches copyright or violates any law, please contact openaccess@qub.ac.uk. 


\section{The multiple origins of sexual size dimorphism in global amphibians}

Daniel Pincheira-Donoso ${ }^{1,6}$, Lilly P. Harvey², Florencia Grattarola ${ }^{3}$, Manuel Jara ${ }^{4}$, Sheena C.

Cotter $^{3}$, Tom Tregenza ${ }^{5}$ \& Dave J. Hodgson ${ }^{5}$

${ }^{1}$ MacroBiodiversity Lab, School of Biological Sciences, Queen's University Belfast, 19 Chlorine Gardens,

Belfast, BT9 5DL, United Kingdom

${ }^{2}$ School of Science and Technology, Department of Biosciences, Nottingham Trent University, Nottingham, NG11 8NS, United Kingdom

${ }^{3}$ School of Life Sciences, University of Lincoln, Brayford Campus, Lincoln, Lincolnshire, LN6 7TS, United Kingdom

${ }^{4}$ Department of Population Health and Pathobiology, College of Veterinary Medicine, North Carolina State University, Raleigh, NC, USA

${ }^{5}$ Centre for Ecology and Conservation, College of Life and Environmental Sciences, University of Exeter, Cornwall Campus, Penryn, TR10 9FE, Cornwall, United Kingdom

${ }^{6}$ Corresponding author: Daniel Pincheira-Donoso, D.Pincheira-Donoso@qub.ac.uk

Running title: sexual dimorphism and biodiversity patterns 


\section{Abstract}

Aim: Body size explains most variation in fitness within animal populations and is therefore under constant selection from ecological and reproductive pressures which often promote its evolution in sex-specific directions, leading to sexual size dimorphism (SSD). Multiple hypotheses have been proposed to explain the vast diversity of SSD across species. These hypotheses emphasise (i) the mate competition benefits to larger male size (sexual selection), (ii) the benefits of larger female size for fecundity (fecundity selection), (iii) the simultaneous benefits of niche divergence for males and females to reduce inter-sexual competition for ecological resources (natural selection), and (iv) the underlying impact of geographic variation in climatic pressures expected to shape large-scale patterns of SSD in synergy with the above selection pressures (e.g., intensification of fecundity selection as breeding seasons shorten). Based on a novel, global-scale amphibian dataset, we address the shortage of large-scale, integrative tests of these four hypotheses.

Location: Global.

Time period: Extant.

Major taxa studied: Class Amphibia.

Methods: Using a >3,500 species dataset spanning body size, ecological, life history, geographic and climatic data, we performed phylogenetic linear models to address the sexual, fecundity, ecological and climatic hypotheses of SSD.

Results: SSD evolution is discordant between anurans and salamanders. Anuran SSD is shaped by climate - male-biased SSD increases with temperature seasonality - and by nesting site. In salamanders, SSD converges across species that occupy the same microhabitat types ('ecodimorphs'), while reproductive or climatic pressures have no effects on their SSD. These contrasts are associated with latitudinal gradients of SSD in anurans, but not in salamanders.

Main conclusions: Amphibian SSD is driven by ecological and climatic pressures, while no roles for sexual or fecundity selection were detected. We show that macroevolutionary processes determined by different forms of selection lead to latitudinal patterns of trait diversity, and the lack of them.

Key words: Fecundity selection, sexual selection, natural selection, climate, life histories, amphibians. 


\section{Introduction}

The optimisation of sex-specific reproductive and ecological performance is rarely achieved by conspecific males and females of similar body size (Andersson, 1994; Fairbairn et al., 2007). Therefore, disruptive selection often drives males and females to evolve different body sizes to enhance their sex-specific fitness (Shine, 1989; Bonduriansky \& Rowe, 2005; Butler et al., 2007; Fairbairn, 2007; Pincheira-Donoso \& Hunt, 2017). This leads to sexual size dimorphism (SSD), one of the most widespread forms of intraspecific adaptive evolution across the animal tree of life (Bolnick \& Doebeli, 2003; Fairbairn et al., 2007).

A range of hypotheses have been suggested to explain the evolution of SSD. Traditionally, SSD has been attributed to sexual selection driving larger male body size - when mating success in males correlates positively with their body size during contests with other males and female choice, male-biased SSD is predicted (Darwin, 1871; Andersson, 1994; Rosenthal, 2017). Alternatively, fecundity selection theory predicts that SSD is female-biased in species where fitness increases with larger brood size (transient fecundity) attained by larger female size (Darwin, 1874; Fairbairn et al., 2007; Nali et al., 2014; PincheiraDonoso \& Hunt, 2017). However, this prediction has been questioned as it ignores the prevalent and simultaneous effects of sexual selection for larger (or smaller) male size (Pincheira-Donoso \& Hunt, 2017). Therefore, larger females that cause female-biased SSD can evolve driven by mechanisms other than fecundity selection, while female-biased SSD may not necessarily correlate with the strength of fecundity selection (Woolbright, 1983; Zamudio, 1998; Cox et al., 2003; Pincheira-Donoso \& Hunt, 2017). A more recent hypothesis (the 'niche divergence hypothesis'), that intersexual competition for ecological resources creates natural selection that drives divergence between males and females, has increasingly gained support (Shine, 1989; Bolnick \& Doebeli, 2003; Pincheira-Donoso et al., 2018). According to this hypothesis, the intensity of intraspecific ecological competition is mitigated by disruptive natural selection driving males and females into different regions of the niche space (Slatkin, 1984; Shine, 1989; Temeles et al., 2000; Bolnick \& Doebeli, 2003; Butler et al., 2007; Meiri et al., 2014; Pincheira-Donoso et al., 2018). Likewise, sexspecific natural selection arising from intrinsic differences in reproductive roles exposes males and females to different ecological pressures within their shared environments (Shine, 1989; Losos et al., 2003). Therefore, this ecological SSD hypothesis makes no predictions about whether males or females are larger, given that either sex can benefit from a larger size (Pincheira-Donoso et al., 2018).

A potential implication of the idea that SSD can be the outcome of different forms of selection is that the macroevolutionary pathways underlying the divergence between the sexes within lineages can influence the geographic patterns of distributions of this trait at large spatial scales. For example, the niche space occupied by sexes undergoing divergence by natural selection can saturate the ecological opportunity 
required for speciation during adaptive radiation (Bolnick \& Doebeli, 2003; Butler et al., 2007; PincheiraDonoso et al., 2018). Therefore, ecological SSD could mirror the outcome of adaptive radiation when character displacement partitions niche space within an area. Across geographic space, this process may inhibit the evolution of macroecological patterns if the same set of resources (e.g., microhabitats) are available in different geographic areas. In contrast, climatic constraints (e.g., length of breeding season) responsible for the intensity of fecundity and sexual selection (Andersson, 1994; Cox et al., 2003; PincheiraDonoso \& Tregenza, 2011) are more likely to create latitudinal patterns of SSD (Pincheira-Donoso \& Hunt, 2017).

Although some studies conducted across vertebrates and invertebrates have implemented largescale approaches to address some of the multiple predictions described above (Cox et al., 2003; Blanckenhorn et al., 2006; Amarello et al., 2010; Dunham et al., 2013; Michael et al., 2014; Joos et al., 2017; Tarr et al., 2019), truly integrative analyses remain anecdotal. The only global-scale studies to date have investigated the relationships between environmental pressures (climate and ecology) and SSD, and have revealed contradictory findings. While an analysis on global turtles showed significant effects of climate and habitat use on SSD (Agha et al., 2018), a study on birds failed to identify any global predictors of SSD (Friedman \& Remes, 2016). Despite these efforts, no global-scale studies exist that investigate the predicted effects of sexual, fecundity and natural selection, and the environmental influences of climate as drivers of SSD, thus preventing wider interpretations about the role of these mechanisms on the evolution of sexual dimorphism.

We created the largest global dataset on SSD for a tetrapod Class, spanning 3,500+ amphibian species ( $43 \%$ of their living diversity). Using phylogenetic analyses based on multiple proxies of all three forms of selection and climate, we test the hypotheses that (i) male-biased SSD evolves in species where the outcome of competition over mates is influenced by fighting among males, relative to species where male-male aggression is absent (Shine, 1979; Andersson, 1994); (ii) fecundity selection promotes larger clutch sizes, attained by evolution of larger female size, leading to the prediction that female-biased SSD increases as a function of increasing fecundity (Darwin, 1874); (iii) different microhabitat structures within habitats create different opportunities for ecological divergence between the sexes, which leads to the prediction that patterns of SSD should converge among species that occupy similar microhabitats, regardless of geographic location and phylogenetic affiliation (Shine, 1989; Losos et al., 2003; Butler et al., 2007; Pincheira-Donoso et al., 2009; Agha et al., 2018); (iv) climatic gradients, through their effects on multiple fitness-relevant traits (e.g., life history traits), shape variation of SSD at large geographic scales. Also, fecundity selection for larger broods intensifies as opportunities for reproduction decline towards more 
seasonal climates, leading to the further prediction that female-biased SSD increases with increasing seasonality and thus, towards higher latitudes (Cox et al., 2003; Pincheira-Donoso \& Tregenza, 2011; Nali et al., 2014).

\section{Methods}

\section{Species data}

We created a dataset spanning SSD and multiple sexual, reproductive, ecological and climatic candidate predictors across a sample of 3,506 amphibian species from all three living orders (Anura or 'anurans', Caudata or 'salamanders', and Gymnophiona or 'caecilians'). The taxonomy follows Frost (2020). The data were collected predominantly from the primary literature, including articles and monographic books, and from field/museum observations (Supplementary Table S1). To collate SSD data, we recorded maximum body size of adult males and females separately. Species for which only young or one individual per sex is known were excluded. For anurans and salamanders, we used snout-vent length (SVL; this is measured as the snout-to-urostyle length in anurans, and snout-to-edge of cloacae in salamanders) as this is the most widely used body size proxy in these groups (Duellman \& Trueb, 1994; Wells, 2007). For caecilians, we used total body length as this is widely, and often the only, documented proxy for size (Pincheira-Donoso et al., 2019). However, most records of body size available for caecilians focus on one overall measure per species or on one of the sexes only. Thus, while multiple patterns of SSD are reported for all three amphibian orders, many analyses were only restricted to anurans and salamanders to reduce the risk of non-credible statistical results obtained from caecilians. SSD for each species was calculated with the formula In(SVLmale/SVLFemale), an intuitive measure that returns negative values for species where females are the larger sex, and positive when males are larger, which has also been shown to perform with robust statistical power (Smith, 1999; Fairbairn, 2007). Species for which male and female body size is the same $(S S D=0)$ were considered sexually monomorphic. This dataset is part of the Global Amphibian Biodiversity Project (GABiP, at www.amphibianbiodiversity.org) initiative.

\section{Sexual and fecundity data}

To address the roles of sexual and fecundity selection as drivers of SSD, we employed a dataset spanning mating and life history traits (Supplementary Table S1). Measures of sexual selection are particularly difficult to obtain unless a species has been under systematic behavioural observations. In addition, multiple traits known to play key roles in mate competition among (mostly male) amphibians, such as chemical and acoustic signals, are not necessarily correlated with body size (Andersson, 1994; Duellman \& Trueb, 1994; 
Wells, 2007; Norris \& Lopez, 2011). In contrast, male-male competition is widely known to create sexual selection for larger male body size (Shine, 1979; Clutton-Brock, 1988; Andersson, 1994), serving as a key proxy for sexual selection. Male-male competition has been documented extensively as a form of mating competition among amphibians (Duellman \& Trueb, 1994; Mathis et al., 1995; Sullivan et al., 1995; Wells, 2007; Sparreboom, 2014), and multiple observations have shown that larger males are more aggressive during the breeding season, and more successful when engaging in contests (Houck, 1988; Sullivan et al., 1995; Camp, 1999; Wells, 2007; Sparreboom, 2014). Therefore, we used male intrasexual aggressive behaviour as a proxy for sexual selection on male size. Data on male-male contests were taken from sources that describe direct agonistic encounters between individuals, whereas inferential observations, such as males avoiding a site when encountering another male, or bite scars in the skin (e.g., Mathis et al., 1995; Sparreboom, 2014), were excluded. Likewise, male traits that have been assumed to be proxies for male combat, such as tusks and spines (Shine, 1979), were also treated as inferential proxies for male fights as they often evolve to optimise functions such as foraging, amplexus, and interspecific defence (Duellman \& Trueb, 1994; Wells, 2007; Han \& Fu, 2013). No evidence for male contests in a species can be due to either lack of the behaviour or lack of observation of the behaviour when it exists (Han \& Fu, 2013). Thus, we limited our sexual selection analyses to comparisons between species in which fighting exists against species where extensive behavioural observations that have reported, for example, nest building, female searching, satellite behaviour, or mating calls, have failed to observe male contests (Han \& Fu, 2013; Sparreboom, 2014). These species were assumed to lack male fighting.

To address the role of fecundity selection, we analysed transient fecundity (brood size) and nesting site preference as factors expected to influence reproductive output (Duellman \& Trueb, 1994; Wells, 2007). To estimate transient fecundity, we obtained the median value calculated from the range of brood sizes recorded per species, often reported as maximum and minimum. When different sources provided different ranges of brood size for the same species, we obtained the median brood size per study and then calculated a single average value for that given species across sources. For hynobiid salamanders that lay eggs into two sacks, clutch size values were not recorded when authors failed to indicate whether the reported number of eggs refers to one or to both sacks combined. We also excluded records of broods that were inferred (rather than observed) to have been laid by a particular species, or when the clutch was suspected to be communal. For nesting site data, each species was assigned to one of five categories depending on whether eggs are laid in water (which only includes water bodies in the ground), the ground (terrestrial sites), in burrows (cavities, under trunks), vegetation (bushes and trees, including the use of small accumulations of water in flowers or between leaves), or in the parental body (gastric or skin-brooder species). These data are 
based on actual observations of individuals occupying those nesting sites. Species for which nesting site was speculated based on, for example, close relatives, were excluded. Similarly, all species for which different literature sources reported conflicting records were excluded (Supplementary Table S1).

\section{Ecological data}

To investigate the role of ecological pressures on SSD, we employed a dataset consisting of two key components of a species niche from which natural selection arises: preference of microhabitat type and diel activity period (Supplementary Table S1). For the microhabitat data, each species was assigned to one of five categories based on their preference for aquatic (strict water-divers), semi-aquatic (species that depend on intermittent contact with water bodies, e.g., swamp-dwellers, species permanently exposed to waterfall showers), terrestrial (predominantly ground-dwellers), vegetation (species that perch on bushes or trees), or

underground ('fossorial', species that, except for breeding seasons, live underground, including both burrows and caves) microhabitat types. For diel activity period data, species were classed as nocturnal, diurnal, cathemeral (active during day and night), or crepuscular (only active in twilight). Records based on inferences stemming from the ecology of closely related species were excluded.

\section{Environmental data}

To address the role of climate on SSD (Pincheira-Donoso \& Hunt, 2017; Agha et al., 2018; Tarr et al., 2019), we created an environmental dataset with multiple predictors obtained using geographic range maps for all the amphibian species for which distributional data are available at the IUCN archive (www.iucnredlist.org). This dataset consists of mean annual temperature (averaged across the 12 months of the year, in degrees Celsius), temperature seasonality (calculated as the standard deviation of the annual mean temperature $x 100$, in degrees Celsius), mean annual precipitation (the averaged amount of rainfall measured in millimetres per year), and precipitation seasonality (coefficient of variation of monthly precipitation across the year). These environmental predictors were obtained from the WorldClim 2 (www.worldclim.org/version2) archive (Hijmans et al., 2005; Fick \& Hijmans, 2017), and are expressed at spatial resolution of 2.5 arcminutes ( $\sim 5 \mathrm{~km}$ at the equator). In addition, we added concentration of atmospheric oxygen as a fifth predictor. Spatial declines in oxygen levels have been shown to create strong selection on life history traits, primarily exerting constraints on success rates of embryo development (Andrews, 2002; Wells, 2007; Lambert \& Wiens, 2013; Pincheira-Donoso et al., 2017). To obtain oxygen levels, we followed the protocol described in Pincheira-Donoso et al. (2017), by first estimating air pressure from the distributional range of each species, using the hypsometric equation $\mathrm{P}=\mathrm{P}_{0} \times(1-0.0065 \times h / T+0.0065 \times h+273.15)^{-5.257}$ 
(Seinfeld \& Pandis, 2016), where P is atmospheric pressure (in $\mathrm{hPa}$ ), $\mathrm{P}$ o represents atmospheric pressure at sea-level (1013.25 hPa or 1atm), $h$ indicates altitude above sea level (in metres), and T indicates environmental temperature (in ${ }^{\circ} \mathrm{C}$ ). Using atmospheric pressure $(\mathrm{P})$, we calculated the proportion of available atmospheric oxygen relative to the baseline $100 \%$ availability of oxygen at sea level with the formula: Oxygen $=\left(P / P_{0}\right) \times 100$ (Seinfeld \& Pandis, 2016; Pincheira-Donoso et al., 2017). We assigned each species a single value per predictor (Supplementary Table S1), calculated as the average of all values obtained for each variable by dividing the geographic range of each species into 2.5 arc-minute grid cells $(\sim 5 \times 5$ kilometres) using ArcGIS 10.2. Finally, we included latitude (midpoint, in degrees from the Equator) extracted from each individual map as a further predictor to test for geographic gradients of SSD.

\section{Statistical and phylogenetic analyses}

We performed phylogenetically-controlled linear models (phylogenetic linearized least squares, PGLS) to investigate the evolution of SSD as a function of the above described predictors. All phylogenetic regression models employed Jetz \& Pyron's (2018) phylogenetic tree for 7,238 amphibian species, from where we extracted all species for which data were available (Supplementary Table S1). Prior to any analyses, we investigated the allometric influence of body size on SSD. This relationship, termed Rensch's rule, states that the magnitude of SSD increases with increasing body size in species in which males are larger, while SSD decreases with increasing body size in species in which females are larger (Abouheif \& Fairbairn, 1997; Fairbairn, 1997; Blanckenhorn et al., 2007a; Pincheira-Donoso \& Tregenza, 2011). To test for Rensch's rule across amphibians, we employed major axis regressions (RMA, model II). This technique offers a suitable approach to test the null hypothesis of isometry $\beta=1.0$ (Sokal \& Rohlf, 1995; Fairbairn, 1997; Blanckenhorn et al., 2007a). When log male body size is plotted on the $y$ axis, and log female body size on $x$, an allometric association consistent with Rensch's rule occurs when variance in $x$ is less than in $y$, and thus, when a hyperallometric or positive allometric relationship is observed (Fairbairn, 1997). Standard errors (SE) and 95\% confidence intervals calculated on error in both $x$ and $y$ for MA slopes are obtained (Blanckenhorn et al., 2007b). To control for phylogenetic effects on SSD, we performed the RMA analyses based on phylogenetic independent contrasts (PIC) of male and female body size, obtained using the R package 'ape' (Paradis et al., 2004).

We then designed multiple PGLS models that separately address the sexual, fecundity, ecological and climatic hypotheses of SSD. For the sexual selection tests, we created PGLS models that compare levels of SSD between species for which male-male fights are known against species in which they have not been observed. In addition to these analyses, we created frequency distribution plots that show the 
distribution of species according to their SSD around a reference line that indicates sexual monomorphism $(S S D=0)$. These plots are designed to show whether the frequency of species without male-male competition tends to show female-biased SSD (left of the zero reference line) relative to the group in which fights exist, which are predicted to be biased towards a higher frequency of species with male-biased SSD. To test for a role of fecundity selection, we first addressed the core prediction that increases in brood size are a function of increasing female body size (Darwin, 1874; Pincheira-Donoso \& Hunt, 2017). The test of this prediction is crucial to subsequently make robust interpretations about the relationship between fecundity and SSD as this association offers more direct evidence of fecundity selection (Cox et al., 2003; Pincheira-Donoso \& Tregenza, 2011). Given the strong positive relationship observed between body size and brood size (see results), our tests of fecundity selection were performed by regressing SSD on clutch size, with control for female body size, to establish the role of variance in reproductive output on intersexual size divergence (see multivariate climatic analyses described from the next paragraph for a further test of fecundity selection's prediction that increasing fecundity is selected for towards more seasonal environments). Finally, to test the ecological hypothesis of SSD (Shine, 1989; Butler et al., 2007; Pincheira-Donoso et al., 2018), we created two sets of alternative models. First, we addressed the question of whether microhabitat-specific natural selection drives convergent evolution of SSD across species that occupy the same microhabitat types, regardless of their phylogenetic affiliation (Losos et al., 2003; Butler et al., 2007; Pincheira-Donoso et al., 2009). This hypothesis predicts 'ecomorphological' SSD (which we term 'ecodimorphs'), and thus, divergent patterns of SSD among species that occupy different microhabitats (Butler et al., 2007). This analysis consisted of phylogenetic ANOVAs quantifying whether variation in SSD differs among the above microhabitat categories, as factors (aquatic, semi-aquatic, terrestrial, vegetation, fossorial). We then performed similar analyses to test whether SSD is predicted across diel activity categories, based on the same adaptive principles described for microhabitat-driven convergence.

Finally, we created PGLS models to investigate large-scale patterns of SSD across climatic and geographic space. We first tested for the role of climate on SSD, performing a series of phylogenetic multiple regressions of SSD on all five climatic predictors described above to determine the exclusive role of environmental pressures on intersexual size divergence. The same multiple regressions were repeated with brood size added to the above climatic predictors in the models, to further investigate whether climate influences SSD once the role of fecundity on SSD is controlled for, given that fecundity selection is expected to intensify as the opportunities for reproduction are compromised towards environments with shorter breeding seasons (Fitch, 1981; Cox et al., 2007; Pincheira-Donoso \& Tregenza, 2011; Pincheira-Donoso \& Hunt, 2017). This test is critical as it complements the conclusions that can be drawn from the fecundity 
selection tests presented in the previous paragraph. In addition to the climatic analyses, we investigated the expression of latitudinal gradients by regressing SSD on latitude - a widely used core geographic predictor to identify biodiversity patterns in macroecology. Importantly, given that latitude is not a mechanistic predictor in itself (rather, multiple selection agents, such as climate, vary with latitude), it was treated independent from the climatic drivers above. Given the loss of statistical power resulting from the differences in sample sizes across the whole range of explanatory variables described this far, a full model confronting all hypotheses based on the inclusion of all predictors was not possible.

All the above analyses were performed for anurans and salamanders separately to establish lineage-specific patterns of SSD evolution (sample sizes for caecilians were often too low to perform analyses independently). These two Orders differ in multiple core features (e.g., body plan, life histories, distribution, genome size), and thus, their responses to selection are expected to differ. In all regressions, continuous predictors were log-transformed to meet assumptions about normality and homogeneity of variance. For every model, we tested the significance of the value of Pagel's lambda, which measures the influence of shared evolutionary history on the divergence of regression residuals among species (Pagel, 1999). All phylogenetic linear models were performed using the packages 'ape' (Paradis et al., 2004), 'nlme' (Pinheiro et al., 2018), and 'caper' (Orme et al., 2012) implemented in R (R Development Core Team, 2017). For the phylogenetic tree with variation of values of SSD through time along the branches (shown in fig. 1), we used a maximum-likelihood phylogenetic reconstruction implemented in the package 'phytools' (Revell, 2012). For the hexagon density scatter plots presented in figure 5 (c, d), we used the approach described in Roll et al. (2017).

To reinforce the inference from our climatic PGLS models, we performed model-averaging analyses using AIC and Akaike model weights to reduce the whole set of models (Burnham \& Anderson, 2002), employing a dredging approach that retains a confidence subset of regression models that lie within 6 AIC units of the most informative model. This approach removes the set of models that have spurious parameter estimates due to poor model fit above the chosen AIC threshold (Richards, 2005; Harrison et al., 2018). The importance of each explanatory variable was judged according to AIC-weighted mean effect sizes averaged across the subset of regression models, and are presented as AIC-weighted slope estimates $+/-95 \%$ confidence intervals to estimate the significance of the effect of each predictor on SSD. Model-averaging analyses were performed using the R package 'MuMIn' (Barton, 2017).

\section{Results}


SSD varies extensively across orders, families and species (Figs. 1 and 2). Female-biased SSD strongly prevailed in all three amphibian orders (Fig. 2). In anurans, SSD is female-biased in $90.8 \%$ of species, malebiased in $7.5 \%$, and monomorphism was observed in $1.7 \%$ of species. In salamanders, $79.2 \%$ of species showed female-biased SSD, $19.1 \%$ male-biased, and $1.8 \%$ are monomorphic (SSD $=0)$. In caecilians, SSD was observed to be female-biased in $81.3 \%$ of species, male-biased in $18.8 \%$, while no monomorphic species were observed (Fig. 2). Anurans showed by far the widest range of variation in SSD (Fig. 2). Regarding allometric effects of body size on SSD (Rensch's rule), our phylogenetic analyses consistently rejected this pattern. The slopes of RMA regressions were not significantly different from 1 for anurans (PICs: slope=1.002 \pm 0.004 , intercept $=-0.001,95 \% \mathrm{Cl}=0.981-1.024$, OLS slope=0.93 $\pm 0.01, n=1264$ ) or for salamanders (PICs: slope $=0.989 \pm 0.017$, intercept $=-0.001,95 \% \mathrm{Cl}=0.941-1.041$, OLS slope $=0.95 \pm 0.02$, $n=147$ ). No test was possible for caecilians.

\section{Sexual selection on SSD}

Our analyses consistently failed to identify a relationship between male contests and SSD. Frequency distributions reveal that the tendencies for female- and male-biased SSD are qualitatively identical when comparing between species with and without male-male competition in both anurans and salamanders (Fig. 4a-d). Phylogenetic analyses confirm this finding, showing that no differences exist in the direction and magnitude of SSD between species in which males engage in fights over access to females, relative to species in which male contests are absent (Table 1; Fig. 4e-f).

\section{Fecundity selection on SSD}

Our analyses show that increases in brood size are strongly associated with larger female body size in anurans and salamanders (Table 1; Fig. 3A; the same tendency was observed, but not tested, in caecilians). However, the prediction that female-biased SSD increases as a function of increasing brood size (controlling for body size) was rejected by our analyses across all amphibians (Table 1; Fig. 3B). In contrast, we found that SSD in anurans differs significantly among species that select different nesting sites. While anuran species that lay eggs in burrows have a tendency for greater degrees of SSD (treated as an absolute magnitude of difference in body size between the sexes), species that lay their eggs on leaves in bushes and trees show a drastic decrease in SSD (Fig. 4i). No such association between SSD and nesting site was observed in salamanders (Table 1), although the greatest extent of SSD was observed among plant egglayers (Fig. 4j), which entirely opposes the pattern observed in anurans. 


\section{Natural selection on SSD}

Analyses investigating the effects of ecological pressures reveal similar degrees of SSD across salamander species that occupy the same microhabitat types, once their phylogenetic origin is controlled for (Table 1). While fossorial salamanders have the lowest degree of SSD, species that occupy vegetation have the highest body size difference between the sexes (Fig. 4h). This finding remains consistent both when distinctions between female-based and male-biased SSD are incorporated into the analyses, and when SSD is treated as an absolute value of size difference between the sexes (Table 1). In contrast, our analyses failed to detect an effect of microhabitat on the SSD of anurans (Table 1; Fig. 4g). These observations were not affected when SSD was treated as a magnitude from female- to male-biased differences, or as an absolute measure of magnitude only (Table 1 ).

\section{Macroecological patterns of SSD through climate and geography}

Analyses on the role of climatic factors identified temperature seasonality as the only significant predictor of spatial variation in SSD in anurans - males increase more relative to females as thermal seasonality increases (Table 2; Fig. 5c). Likewise, the model containing brood size added to all five climatic predictors revealed the exact same relationship (Table 2), while the remaining predictors have no effects. The modelaveraging analyses using the same sets of predictors strongly confirmed temperature seasonality as the only driver of anuran SSD, with and without brood size included (Table 2). In contrast, the same analyses performed on salamanders failed to identify a role for climate on SSD (Table 2; Fig. 5d).

The geographic analyses of SSD were consistent with these findings. While no latitudinal gradients (based on absolute values of latitude, ignoring whether the gradient is south or north) of SSD were observed in salamanders globally (Table 2, Fig. 5b), we observed a significant increase in SSD with increasing latitude in anurans globally (i.e., males increase more relative to females with increasing latitude; Table 2, Fig. 5a). Intriguingly, the spatial patterns shown in figure $5(a, b)$ suggest that the latitudinal gradients of SSD may differ among geographic regions of the world, particularly within anurans. A further set of analyses investigating the geographic patterns of anuran SSD within regions separately, confirmed the same positive association between SSD and latitude within the Americas $\left(n=1366, \lambda=0.58, R^{2}=0.01\right.$, estimate $=0.001$, $F_{1,1364}=8.07, P<0.01$, Fig. $5 a$; although distinctive patterns between North and South America exist: femalebiased SSD increases with latitude in the former, and male-biased SSD in the latter) and the Eurasian region ( $n=377, \lambda=0.62, R^{2}=0.03$, estimate $=0.003, F_{1,375}=10.97, P=0.001$, Fig. $5 a$ ). Interestingly, however, the 
latitudinal gradient of anuran SSD is reversed in Africa, where female size increases more relative to male size with increasing latitude $\left(n=349, \lambda=0.54, R^{2}=0.02\right.$, estimate $=-0.002, F_{1,347}=5.51, P=0.02$, Fig. $\left.5 a\right)$. The same region-specific analyses performed in salamanders showed no relationships between SSD and latitude, consistent with the global model.

\section{Discussion}

Our study reveals the distinctive factors driving the evolution of sexual size dimorphism across amphibian orders. In anurans, SSD is associated with climatic gradients in temperature seasonality - a phenomenon that shapes latitudinal gradients of SSD - and with nesting site occupation. These findings provide globalscale evidence suggesting that selection for divergence between the sexes is significantly influenced by variation in the length of the breeding season (Cox et al., 2003; Pincheira-Donoso \& Tregenza, 2011; Pincheira-Donoso \& Hunt, 2017), and by the constraints that nesting structures exert on reproduction (Nali et al., 2014). These two sources of selection on SSD are likely to operate synergistically. In fact, although our analyses failed to identify a relationship between increasing fecundity and female-biased SSD, in contrast with previous studies conducted on frogs (e.g., Han \& Fu, 2013), we found strong evidence that larger females produce larger broods, and a tendency for brood size to increase with increasing latitude (as shown by the negative association between fecundity and SSD; see table 2). These findings are consistent with fecundity selection theory, which predicts evolution of larger broods mediated by larger females towards environments where reproductive opportunities are reduced - mostly regions with shorter breeding seasons (Pincheira-Donoso \& Hunt, 2017). At the same time, this evidence reinforces the view that a link between the intensification of fecundity selection and female-biased SSD is incidental, rather than general, and dependent on the action of multiple other sources of selection on body size, such as male-specific sexual selection for larger body size (Zamudio, 1998; Nali et al., 2014; Pincheira-Donoso \& Hunt, 2017). In contrast, variation in SSD in salamanders is associated with use of microhabitat types. This link suggests a role for natural selection driving convergent evolution in SSD. Importantly, our analyses failed to identify a role for male-male competition-mediated sexual selection in the evolution of SSD across all amphibian clades, as previously observed in anurans (Han \& Fu, 2013; Nali et al., 2014).

Why anurans and salamanders have followed such discordant routes in the evolution of SSD remains an open question. The answer may be linked to their contrasting life history features and biogeographic patterns. Given the strong effects of climate on fecundity (Jetz et al., 2008; Pincheira-Donoso \& Hunt, 2017), the evolution of the truly global distribution of anurans is expected to have exposed these 
amphibians to a much wider range of climatic pressures, leading to a much wider range of life history adaptations to these demands, such as their extreme interspecific variation in clutch size $(1$ to $>80,000$ eggs). In contrast, the global geographic range of salamanders is considerably more restricted than in anurans (Sparreboom, 2014; Pough et al., 2015), leading to a much narrower range of climatic pressures that are likely to influence selection on life history traits (e.g., their narrow variation in clutch size from 2 to $<3,800$ eggs). Yet, a concrete explanation for the association between SSD and microhabitat occupation in salamanders would be unnecessarily speculative at present.

A range of further evolutionary contrasts between anurans and salamanders is likely to predispose their processes of diversification to follow alternatives trajectories, which may contribute to explain their distinct patterns of SSD. In addition to differences in fecundity, fertilisation is external in $\sim 90 \%$ of anuran species, whereas $\sim 90 \%$ of salamanders have internal fertilisation via spermatophores (Duellman \& Trueb, 1994; Pough et al., 2004; Wells, 2007). Also, while genome size in anurans is roughly comparable with that of most tetrapods, the exceptionally large genomes of salamanders can be up to ten times the size of the next-largest tetrapod genomes (Canapa et al., 2015; Kapusta et al., 2017; Liedtke et al., 2018). These differences are expected to influence how selection shapes both lineages. For example, climate is thought to affect the evolution of genome size in anurans (but not in salamanders), which has been hypothesised to be caused by the life history contrasts between these groups (Liedtke et al., 2018). Therefore, the answer to their different patterns of evolution may derive from multiple factors (Nali et al., 2014).

\section{The influence of macroevolution on macroecological patterns of biodiversity}

The contrasting patterns of SSD observed between anurans and salamanders suggest that the different forms of selection associated with intersexual divergence within each order may play a role in their configuration of global patterns of SSD distribution. When the evolution of a trait is shaped by selection from factors that vary geographically (e.g., climate), a macroecological pattern of trait variation can be expected. This is the case for anurans, in which SSD varies following latitudinal gradients associated with geographic gradients in temperature seasonality. Multiple other components of biodiversity conform to this process. For example, the evolution of life history traits associated with fecundity (e.g., clutch size, egg size, parity) can be strongly shaped by selection from climate (Shine, 2005; Jetz et al., 2008; Pincheira-Donoso et al., 2013; Pincheira-Donoso \& Hunt, 2017; Meiri et al., 2020). Thus, the configuration of geographic gradients in the variation of these climate-sensitive traits is expected (Pincheira-Donoso \& Hunt, 2017; Tarr et al., 2019).

In contrast, when selection arises from interspecific competition over finite resources that promote mitigation of conflicts via niche partitioning at local-scale (e.g., character displacement), macroecological 
patterns are expected to be superseded by within-assemblage diversification of the trait. This is the case for interspecific diversity of SSD in salamanders, which seems to be partitioned by the adaptation of species to different microhabitat structures at local scales. Thus, if the same array of ecological resources subject to interspecific competition that are available within an area (e.g., a suite of microhabitat types) are available at different locations along a geographic gradient, multiple replicated sets of 'ecodimorphs' across regions are expected to evolve, eroding a geographic signal (Butler et al., 2007; Pincheira-Donoso et al., 2018). This scenario is observed among replicated community structures of, for example, anole lizards across the Caribbean, which have extensively diversified within islands, without a macroecological signature of trait variation through geographic space (Losos, 2009). Consequently, we expect that processes of diversification driven by competition over limited resources (predominantly adaptive radiations) are more likely to prevent the evolution of large-scale geographic patterns of trait diversity, while processes shaped by geographically varying selection shape macroecological patterns. Our global analyses on amphibians support these expectations.

\section{Acknowledgements}

DPD is indebted to Queen's University Belfast and the School of Biological Sciences for a joint start-up grant that played a key role in the completion of this study. This study has received key financial support from The Environment Now programme, funded by $\mathrm{O} 2$ and the National Lottery's Big Lottery Fund through the Our Bright Future programme, and managed by the National Youth Agency, via a grant awarded to LPH. FG is fully funded by a PhD scholarship awarded by the Agencia Nacional de Investigación e Innovación (ANII) of Uruguay. Two anonymous referees and the AE made insightful observations that contributed to improve the quality and strength of our manuscript.

Data availability statement: All the datasets used in this study are available as supplementary material to the main article, and will be made open-access at the GABiP initiative's repository at http://www.amphibianbiodiversity.org upon publication.

Biosketch: Daniel Pincheira-Donoso is interested in the links between evolutionary theory and large-scale patterns of biodiversity. His research investigates the ecological sources of natural selection that drive the origin, distribution and extinction of biodiversity at broad spatial and temporal scales. 


\section{References}

Abouheif, E. \& Fairbairn, D.J. (1997) A comparative analysis of allometry for sexual size dimorphism: assessing Rensch's rule. American Naturalist, 149, 540-562.

Agha, M., Ennen, J.R., Nowakowski, A.J., Lovich, J.E. \& Sweat, S. C.Todd, B.D. (2018) Macroecological patterns of sexual size dimorphism in turtles of the world. Journal of Evolutionary Biology, 31, 336-345.

Amarello, M., Nowak, E.M., Taylor, E.N., Schuett, G.W., Repp, R.A., Rosen, P.C. \& Hardy, D.L. (2010) Potential environmental influences on variation in body size and sexual size dimorphism among Arizona populations of the western diamond-backed rattlesnake (Crotalus atrox). Journal of Arid Environments, 74, 1443-1449.

Andersson, M. (1994) Sexual selection, Princeton University Press, Princeton.

Andrews, R.M. (2002) Low oxygen: a constraint on the evolution of viviparity in reptiles. Physiological and Biochemical Zoology, 75, 145-154.

Barton, K. (2017) MuMIn: Multi-model inference. R package version 1.40.0, R Foundation for Statistical Computing, Vienna.

Blanckenhorn, W.U., Dixon, A.F.G., Fairbairn, D.J., Foellmer, M.W., Gibert, P., van der Linde, K., Meier, R., Nylin, S., Pitnick, S., Schoff, C., Signorelli, M., Teder, T. \& Wiklund, C. (2007a) Proximate causes of Rensch's rule: does sexual size dimorphism in arthropods result from sex differences in development time? American Naturalist, 169, 245-257.

Blanckenhorn, W.U., Meier, R. \& Teder, T. (2007b) Rensch's rule in insects: patterns among and within species. Sex, size \& gender roles. Evolutionary studies of sexual size dimorphism (ed. by D.J. Fairbairn), W.U. Blanckenhorn), and T. Szekely), pp. 60-70. Oxford University Press, Oxford. Blanckenhorn, W.U., Stillwell, R.C., Young, K.A., Fox, C.W. \& Ashton, K.G. (2006) When Rensch meets Bergmann: does sexual size dimorphism change systematically with latitude? Evolution, 60, 20042011.

Bolnick, D.I. \& Doebeli, M. (2003) Sexual dimorphism and adaptive speciation: two sides of the same ecological coin. Evolution, 57, 2433-2449.

Bonduriansky, R. \& Rowe, L. (2005) Intralocus sexual conflict and the genetic architecture of sexually dimorphic traits in Prochyliza xanthostoma (Diptera: Piophilidae). Evolution, 59, 1965-1975.

Burnham, K.B. \& Anderson, D. (2002) Model selection and multi-model inference: a practical informationtheoretic approach, Springer Verlag, New York.

Butler, M.A., Sawyer, S.A. \& Losos, J.B. (2007) Sexual dimorphism and adaptive radiation in Anolis lizards. Nature, 447, 202-205. 
Camp, C.D. (1999) Intraspecific aggressive behavior in southeastern small species of Plethodon: inferences for the evolution of aggression in terrestrial salamanders. Herpetologica, 55, 248-254.

Canapa, A., Barucca, M., Biscotti, M.A., Forconi, M. \& Olmo, E. (2015) Transposons, genome size, and evolutionary insights in animals. Cytogenetic and Genome Research, 147, 217-239.

Clutton-Brock, T.H. (1988) Reproductive success, Chicago University Press, Chicago.

Cox, R.M., Butler, M. \& John-Alder, H.B. (2007) The evolution of sexual size dimorphism in reptiles. Sex, size \& gender roles. Evolutionary studies of sexual size dimorphism (ed. by D.J. Fairbairn), W.U. Blanckenhorn), and T. Szekely), pp. 38-49. Oxford University Press, Oxford.

Cox, R.M., Skelly, S.L. \& John-Alder, H.B. (2003) A comparative test of adaptive hypotheses for sexual size dimorphism in lizards. Evolution, 57, 1653-1669.

Darwin, C. (1874) The descent of man and selection in relation to sex. Second Edition, Appleton, New York.

Darwin, C. (1871) The descent of man and selection in relation to sex, John Murray, London.

Duellman, W.E. \& Trueb, L. (1994) Biology of Amphibians, Johns Hopkins University Press, Maryland.

Dunham, A.E., Maitner, B.S., Razafindratsima, O.H., Simmons, M.C. \& Roy, C.L. (2013) Body size and sexual size dimorphism in primates: influence of climate and net primary productivity. Journal of Evolutionary Biology, 26, 2312-2320.

Fairbairn, D.J. (1997) Allometry for sexual size dimorphism: pattern and process in the coevolution of body size in males and females. Annual Review of Ecology, Evolution and Systematics, 28, 659-687.

Fairbairn, D.J. (2007) The enigma of sexual size dimorphism. Sex, size \& gender roles. Evolutionary studies of sexual size dimorphism (ed. by D.J. Fairbairn), W.U. Blanckenhorn), and T. Szekely), pp. 1-10. Oxford University Press, Oxford.

Fairbairn, D.J., Blanckenhorn, W.U. \& Szekely, T. (2007) Sex, size \& gender roles. Evolutionary studies of sexual size dimorphism, Oxford University Press, Oxford.

Fick, S.E. \& Hijmans, R.J. (2017) Worldclim 2: New 1-km spatial resolution climate surfaces for global land areas. International Journal of Climatology, 37, 4302-4315.

Fitch, H.S. (1981) Sexual size differences in reptiles. University of Kansas Museum of Natural History, Miscellaneous Publications, 70, 1-72.

Friedman, N.R. \& Remes, V. (2016) Global geographic patterns of sexual size dimorphism in birds: support for a latitudinal trend? Ecography, 39, 17-25.

Frost, D.R. (2020) Amphibian Species of the World: an Online Reference. Version 6.0 (July 2020). American Museum of Natural History, New York, USA, Electronic.

Han, X. \& Fu, J. (2013) Does life history shape sexual size dimorphism in anurans? A comparative analysis. 
BMC Evolutionary Biology, 13, 27.

Harrison, X.A., Donaldson, L., Correa-Cano, M.E., Evans, J., Fisher, D.N., Goodwin, C.E.D., Robinson, B.S., Hodgson, D.J. \& Inger, R. (2018) A brief introduction to mixed effects modelling and multi-model inference in ecology. PeerJ, 6, e4794.

Hijmans, R.J., Cameron, S.E., Parra, J.L., Jones, P.G. \& Jarvis, A. (2005) Very high resolution interpolated climate surfaces for global land areas. International Journal of Climatology, 25, 1965-1978.

Houck, L.D. (1988) The effect of body size on male courtship success in a plethodontid salamander. Animal Behaviour, 36, 837-842.

Jetz, W. \& Pyron, R.A. (2018) The interplay of past diversification and evolutionary isolation with present imperilment across the amphibian tree of life. Nature Ecology \& Evolution, 2, 850-858.

Jetz, W., Sekercioglu, C.H. \& Bohning-Gaese, K. (2008) The worldwide variation in avian clutch size across species and space. PLoS Biology, 6, e303.

Joos, J., Kirchner, M., Vamberger, M., Kaviani, M., Rahimibashar, M.R., Fritz, U. \& Muller, J. (2017) Climate and patterns of body size variation in the European pond turtle, Emys orbicularis. Biological Journal of the Linnean Society, 122, 351-365.

Kapusta, A., Suh, A. \& Feschotte, C. (2017) Dynamics of genome size evolution in birds and mammals. Proceedings of the National Academy of Sciences of the United States of America, 114, E1460-E1469.

Lambert, S.M. \& Wiens, J.J. (2013) Evolution of viviparity: a phylogenetic test of the cold-climate hypothesis in phrynosomatid lizards. Evolution, 67, 2614-2630.

Liedtke, H.C., Gower, D.J., Wilkinson, M. \& Gomez-Mestre, I. (2018) Macroevolutionary shift in the size of amphibian genomes and the role of life history and climate. Nature Ecology \& Evolution, 2, 1792-1799.

Losos, J.B. (2009) Lizards in an evolutionary tree. Ecology and adaptive radiation of anoles, University of California Press, Berkeley.

Losos, J.B., Butler, M. \& Schoener, T.W. (2003) Sexual dimorphism in body size and shape in relation to habitat use among species of Caribbean Anolis lizards. Lizard social behaviour (ed. by S.F. Fox), J.K. McCoy), and T.A. Baird), pp. 356-380. John Hopkins University Press, Baltimore and London.

Mathis, A., Jaeger, R.G., Hubert-Keen, W., Ducey, P.K., Walls, S.C. \& Buchanan, B.W. (1995) Aggression and territoriality by salamanders and a comparison with the territorial behavior of frogs. Amphibian Biology. Vol. 2. Social Behaviour (ed. by H. Heatwole) and S.K. Sullivan), pp. 633-676. Surrey Beatty \& Sons, New South Wales.

Meiri, S., Avila, L., Bauer, A.M., Chapple, D.G., Das, I., Doan, T.M., Doughty, P., Ellis, R., Grismer, L., Kraus, F., Morando, M., Oliver, P., Pincheira-Donoso, D., Ribeiro-Junior, M.A., Shea, G., Torres-Carvajal, O., 
Slavenko, A. \& Roll, U. (2020) The global diversity and distribution of lizard clutch sizes. Global Ecology and Biogeography, 29, 1515-1530.

Meiri, S., Kadison, A.E., Novosolov, M., Pafilis, P., Foufopoulos, J., Itescu, Y., Raia, P. \& Pincheira-Donoso, D. (2014) The number of competitor species is unlinked to sexual dimorphism. Journal of Animal Ecology, 83, 1302-1312.

Michael, D.R., Banks, S.C., Piggott, M.P., Cunningham, R.B., Crane, M., MacGregor, C., McBurney, L. \& Lindenmayer, D.B. (2014) Geographical variation in body size and sexual size dimorphism in an Australian lizard, Boulenger's skink (Morethia boulengeri). PLoS One, 9, e109830.

Nali, R.C., Zamudio, K.R., Haddad, C.F.B. \& Prado, C.P.A. (2014) Size-dependent selective mechanisms on males and females and the evolution of sexual size dimorphism in frogs. American Naturalist, 184, 727-740.

Norris, D.O. \& Lopez, K.H. (2011) Hormones and reproduction of vertebrates. Amphibians. Volume 2, Academic Press, London.

Orme, C.D.L., Freckleton, R.P., Thomas, G.H., Petzoldt, T., Fritz, S.A. \& Isaac, N.J.B. (2012) CAPER: Comparative Analyses of Phylogenetics and Evolution in R. R Package, Version 0.

Pagel, M. (1999) Inferring the historical patterns of biological evolution. Nature, 401, 877-884.

Paradis, E., Claude, J. \& Strimmer, K. (2004) APE: analyses of phylogenetics and evolution in R language. Bioinformatics, 20, 289-290.

Pincheira-Donoso, D., Hodgson, D.J., Stipala, J. \& Tregenza, T. (2009) A phylogenetic analysis of sexspecific evolution of ecological morphology in Liolaemus lizards. Ecological Research, 24, 1223-1231.

Pincheira-Donoso, D. \& Hunt, J. (2017) Fecundity selection theory: concepts and evidence. Biological Reviews, 92, 341-356.

Pincheira-Donoso, D., Jara, M., Reaney, A., García-Roa, R., Saldarriaga-Córdoba, M. \& Hodgson, D.J. (2017) Hypoxia and hypothermia as rival agents of selection driving the evolution of viviparity in lizards. Global Ecology and Biogeography, 26, 1238-1246.

Pincheira-Donoso, D., Meiri, S., Jara, M., Olalla-Tarraga, M.A. \& Hodgson, D.J. (2019) Global patterns of body size evolution are driven by precipitation in legless amphibians. Ecography, 42, 1682-1690.

Pincheira-Donoso, D. \& Tregenza, T. (2011) Fecundity selection and the evolution of reproductive output and sex-specific body size in the Liolaemus lizard adaptive radiation. Evolutionary Biology, 38, 197207.

Pincheira-Donoso, D., Tregenza, T., Butlin, R.K. \& Hodgson, D.J. (2018) Sexes and species as rival units of niche saturation during community assembly. Global Ecology \& Biogeography, 27, 593-603. 
Pincheira-Donoso, D., Tregenza, T., Witt, M.J. \& Hodgson, D.J. (2013) The evolution of viviparity opens opportunities for lizard radiation but drives it into a climatic cul-de-sac. Global Ecology and Biogeography, 22, 857-867.

Pinheiro, J., Bates, D., DebRoy, S. \& Sarkar, D. (2018) nlme: linear and nonlinear mixed effects models. $R$ package version 3, 1-137.

Pough, F.H., Andrews, R.M., Cadle, J.E., Crump, M.L. \& Wells, K.D. (2004) Herpetology, Third. Pearson, Prentice Hall, New Jersey.

Pough, F.H., Andrews, R.M., Crump, M.L., Savitzky, A.H., Wells, K.D. \& Brandley, M.C. (2015) Herpetology, Oxford University Press, Oxford.

R Development Core Team (2017) R: A language and environment for statistical computing, R Foundation for Statistical Computing, Vienna.

Revell, L.J. (2012) Phytools: an R package for phylogenetic comparative biology (and other things). Methods in Ecology and Evolution, 3, 217-223.

Richards, S.A. (2005) Testing ecological theory using the information-theoretic approach: examples and cautionary results. Ecology, 86, 2805-2814.

Roll, U., Feldman, A., Novosolov, M., Allison, A., Bauer, A.M., Bernard, R., Böhm, M., Castro-Herrera, F., Chirio, L., Collen, B., Colli, G.R., Dabool, L., Das, I., Doan, T.M., Grismer, L.L., Hoogmoed, M., Itescu, Y., Kraus, F., LeBreton, M., Lewin, A., Martins, M., Maza, E., Meirte, D., Nagy, Z.T., de C. Nogueira, C., Pauwels, O.S.G., Pincheira-Donoso, D., Powney, G.D., Sindaco, R., Tallowin, O.J.S., Torres-Carvajal, O., Trape, J.-F., Vidan, E., Uetz, P., Wagner, P., Wang, Y., Orme, C.D.L., Grenyer, R. \& Meiri, S. (2017) The global distribution of tetrapods reveals a need for targeted reptile conservation. Nature Ecology \& Evolution, 1, 1677-1682.

Rosenthal, G.G. (2017) Mate choice. The evolution of sexual decision making from microbes to humans, Princeton Uinversity Press, New Jersey.

Seinfeld, J.H. \& Pandis, S.N. (2016) Atmospheric chemistry and physics: from air pollution to climate change, John Wiley \& Sons, New Jersey.

Shine, R. (1989) Ecological causes for the evolution of sexual dimorphism: a review of the evidence. Quarterly Review of Biology, 64, 419-464.

Shine, R. (2005) Life-history evolution in reptiles. Annual Reviews of Ecology, Evolution and Systematics, 36, 23-46.

Shine, R. (1979) Sexual selection and sexual dimorphism in the Amphibia. Copeia, 1979, 297-306.

Slatkin, M. (1984) Ecological causes of sexual dimorphism. Evolution, 38, 622-630. 
Smith, R.J. (1999) Statistics of sexual size dimorphism. Journal of Human Evolution, 36, 423-459.

Sokal, R.R. \& Rohlf, F.J. (1995) Biometry: the principles and practice of statistics in biological research, W. H. Freeman, California.

Sparreboom, M. (2014) Salamanders of the Old World. The salamanders of Europe, Asia and Northern Africa, KNNV Publishing, The Netherlands.

Sullivan, K.S., Ryan, M.J. \& Verrell, P.A. (1995) Female choice and mating system structure. Amphibian Biology. Vol. 2. Social Behaviour (ed. by H. Heatwole) and B.K. Sullivan), pp. 469-517. Surrey Beatty \& Sons, Sydney.

Tarr, S., Meiri, S., Hicks, J.J. \& Algar, A.C. (2019) A biogeographic reversal in sexual size dimorphism along a continental temperature gradient. Ecography, 42, 706-716.

Temeles, E.J., Pan, I.L., Brennan, J.L. \& Horwitt, J.N. (2000) Evidence for ecological causation of sexual dimorphism in a hummingbird. Science, 289, 441-443.

Wells, K.D. (2007) The ecology and behavior of Amphibians, Chicago University Press, Chicago.

Woolbright, L.L. (1983) Sexual selection and size dimorphism in anuran amphibia. American Naturalist, 121, $110-119$.

Zamudio, K.R. (1998) The evolution of female-biased sexual size dimorphism: a population-level comparative study in horned lizards (Phrynosoma). Evolution, 52, 1821-1833. 


\section{TABLES}

Table 1. Relationships between proxies of sexual, fecundity and natural selection and the global diversity of SSD across amphibians. All analyses have been performed separately for anurans and salamanders, while caecilians have been excluded given low sample sizes. Fecundity refers to transient fecundity (i.e., brood size). Phylogenetic analyses of nesting site and microhabitats as predictors have been performed twice for each order, first with SSD treated as a measure of male- (positive values) and female-biased (negative values) dimorphism, and second, with SSD treated as a measure of absolute magnitude of size difference between the sexes where all values are treated as positive (see footnotes). Most models showed significant phylogenetic signal, estimated using Pagel's $\lambda$ (1999) - see text for details.

\begin{tabular}{|c|c|c|c|c|c|c|c|}
\hline Models & $\lambda$ & $n$ & $R^{2}$ & $F(\mathrm{df})$ & $t$ & Estimate & $P$ \\
\hline \multicolumn{8}{|c|}{ Fecundity Selection } \\
\hline \multicolumn{8}{|l|}{ Fecundity SVL } \\
\hline Anurans & 0.838 & 1441 & 0.29 & $588.6(1,1439)$ & 24.26 & 1.831 & $<0.001$ \\
\hline Salamanders & 0.812 & 151 & 0.062 & $9.89(1,149)$ & 3.145 & 0.909 & $<0.01$ \\
\hline \multicolumn{8}{|c|}{ SSD Fecundity ${ }^{*}$} \\
\hline Anurans & 0.71 & 1441 & - & $0.01(1,1438)$ & -0.09 & -0.0003 & 0.926 \\
\hline Salamanders & 0.64 & 151 & - & $0.078(1,148)$ & -0.28 & -0.0017 & 0.781 \\
\hline \multicolumn{8}{|c|}{ SSD Nesting Site } \\
\hline Anurans $^{a}$ & 0.714 & 970 & - & $8.68(1,968)$ & 2.946 & 0.014 & 0.003 \\
\hline Anurans ${ }^{b}$ & 0.697 & 970 & - & $8.65(1,968)$ & -2.941 & -0.012 & 0.003 \\
\hline Salamanders ${ }^{a}$ & 0.871 & 91 & - & $3.00(1,89)$ & 1.733 & 0.022 & 0.087 \\
\hline Salamanders ${ }^{b}$ & 0.049 & 91 & - & $3.27(1,89)$ & 1.807 & 0.013 & 0.074 \\
\hline \multicolumn{8}{|c|}{ Sexual Selection } \\
\hline \multicolumn{8}{|c|}{ Male-male competition } \\
\hline Anurans & 0.701 & 621 & - & $0.15(1,619)$ & 0.389 & 0.005 & 0.697 \\
\hline Salamanders & 0.9 & 74 & - & $0.016(1,72)$ & -0.127 & -0.003 & 0.899 \\
\hline \multicolumn{8}{|c|}{ Natural Selection } \\
\hline \multicolumn{8}{|c|}{ SSD Microhabitat } \\
\hline Anurans $^{a}$ & 0.626 & 2349 & - & $0.53(1,2347)$ & 0.729 & 0.002 & 0.466 \\
\hline Anurans ${ }^{b}$ & 0.606 & 2349 & - & $0.32(1,2347)$ & -0.569 & -0.002 & 0.569 \\
\hline Salamanders ${ }^{a}$ & 0.630 & 270 & - & $4.73(1,268)$ & 2.175 & 0.012 & 0.03 \\
\hline Salamanders ${ }^{b}$ & 0.597 & 270 & - & $8.30(1,268)$ & -2.881 & -0.013 & $<0.01$ \\
\hline \multicolumn{8}{|c|}{ SSD Diel Activity } \\
\hline Anurans & 0.680 & 1635 & - & $1.66(2,1633)$ & 1.290 & 0.006 & 0.197 \\
\hline Salamanders & 0.399 & 160 & - & $1.67(2,158)$ & -1.292 & -0.013 & 0.198 \\
\hline
\end{tabular}

${ }^{a}$ Female-biased SSD as negative values and male-biased SSD as positive values.

${ }^{b} S S D$ as a measure of absolute magnitude of body size differences.

${ }^{*}$ Results from an analysis of covariance with body size added as covariate. Estimate and $t$-value were obtained from a PGLS. 
Table 2. Climatic and geographic drivers of amphibian SSD. All phylogenetic analyses (PGLS) performed separately for anurans and salamanders (caecilians are excluded given low sample sizes). Environmental analyses are based on multiple regression models (MRM) with mean annual temperature, temperature seasonality, mean annual precipitation, precipitation seasonality and oxygen concentrations as predictors. Geographic analyses include only latitude as predictor. The bottom subsection of the table shows the same MRM analyses controlling for transient fecundity $(\mathrm{Fec})$. For each MRM we report the slope and $95 \% \mathrm{Cl}$ of the drivers returned by model-averaging analyses given their threshold delta-AIC $<6$ (drivers with delta-AIC $>6$ are not shown). Among these returned predictors, significant predictors are in boldface. Most models showed significant phylogenetic signal.

\begin{tabular}{|c|c|c|c|c|c|c|c|c|}
\hline \multirow[b]{2}{*}{ Models } & \multirow[b]{2}{*}{$n$} & \multicolumn{5}{|c|}{ PGLS } & \multicolumn{2}{|c|}{ Model-Averaging Analyses } \\
\hline & & $\lambda$ & $R^{2}$ & $F$ & $t$ & $P$ & Slope & $95 \% \mathrm{Cl}$ \\
\hline \multicolumn{9}{|l|}{ SSD Predictors } \\
\hline \multicolumn{9}{|l|}{ Anurans } \\
\hline (a) MRM & 2649 & 0.626 & 0.01 & 4.52 & - & $<0.001$ & - & - \\
\hline Annual Temperature & - & - & - & - & 1.20 & 0.229 & - & - \\
\hline Temperature Seasonality & - & - & - & - & 3.62 & $<0.001$ & 0.039 & $(0.0214,0.0585)$ \\
\hline Annual Precipitation & - & _- & - & - & 0.84 & 0.399 & - & - \\
\hline Precipitation Seasonality & - & - & - & - & 0.72 & 0.473 & - & - \\
\hline Oxygen & - & - & - & - & -1.79 & 0.073 & -0.035 & $(-0.0890,0.0199)$ \\
\hline (b) Latitude & 2709 & 0.614 & 0.002 & 5.73 & 2.39 & 0.02 & - & - \\
\hline \multicolumn{9}{|l|}{ Salamanders } \\
\hline (a) MRM & 290 & 0.616 & 0.003 & 0.187 & - & 0.967 & - & - \\
\hline Annual Temperature & - & - & - & - & 0.54 & 0.588 & - & - \\
\hline Temperature Seasonality & - & - & - & - & 0.78 & 0.435 & - & - \\
\hline Annual Precipitation & - & - & - & - & 0.07 & 0.943 & - & - \\
\hline Precipitation Seasonality & - & - & - & - & -0.15 & 0.884 & - & - \\
\hline Oxygen & - & - & - & - & -0.60 & 0.549 & -0.013 & $(-0.1239,0.0986)$ \\
\hline (b) Latitude & 298 & 0.651 & 0.0001 & 0.032 & -0.18 & 0.857 & - & - \\
\hline
\end{tabular}

\section{SSD Fec+Predictors}

\section{Anurans}

MRM

Fecundity

Annual Temperature

Temperature Seasonality

Annual Precipitation

Precipitation Seasonality

Oxygen

$\begin{array}{lll}1356 & 0.704 & 0.03 \\ - & - & - \\ - & - & - \\ - & - & - \\ - & - & - \\ - & - & - \\ - & - & -\end{array}$

6.14
-
-
-
-
-
-

$\begin{array}{ll}- & <0.001 \\ -4.78 & <0.001 \\ 0.85 & 0.397 \\ 2.97 & 0.003 \\ -0.57 & 0.570 \\ 0.01 & 0.991 \\ -1.34 & 0.180\end{array}$

$\begin{array}{ll}- & - \\ -\mathbf{0 . 0 1 4} & \mathbf{( - 0 . 0 1 9 1 , ~ - 0 . 0 0 8 2 )} \\ - & - \\ \mathbf{0 . 0 5 1} & \mathbf{( 0 . 0 2 6 9 , 0 . 0 7 5 1 )} \\ - & - \\ - & - \\ -0.050 & (-0.1316,0.0306)\end{array}$

\section{Salamanders}

MRM

Fecundity

Annual Temperature

141

$0.192 \quad 0.04$

0.87

$-$ 


\begin{tabular}{lllllllll}
\hline Annual Precipitation & - & - & - & - & 0.24 & 0.811 & - & - \\
Precipitation Seasonality & - & - & - & - & -1.48 & 0.140 & - & - \\
Oxygen & - & - & - & - & -0.55 & 0.585 & 0.025 & $(-0.1046,0.1552)$ \\
\hline
\end{tabular}




\section{FIGURES}

Figure 1. Phylogenetic patterns of sexual size dimorphism across families of living amphibians. The tree shows the distribution of median SSD across species per families along the branches, and the bar below provides the colour codes for levels of both male- (positive) and female-biased (negative) SSD. The predominant tendency is for female-biased SSD, with the most extreme cases of female-biased SSD observed among anurans (Ceratophryidae, Craugastoridae, Ranidae, among others). See methods for details about SSD calculations.

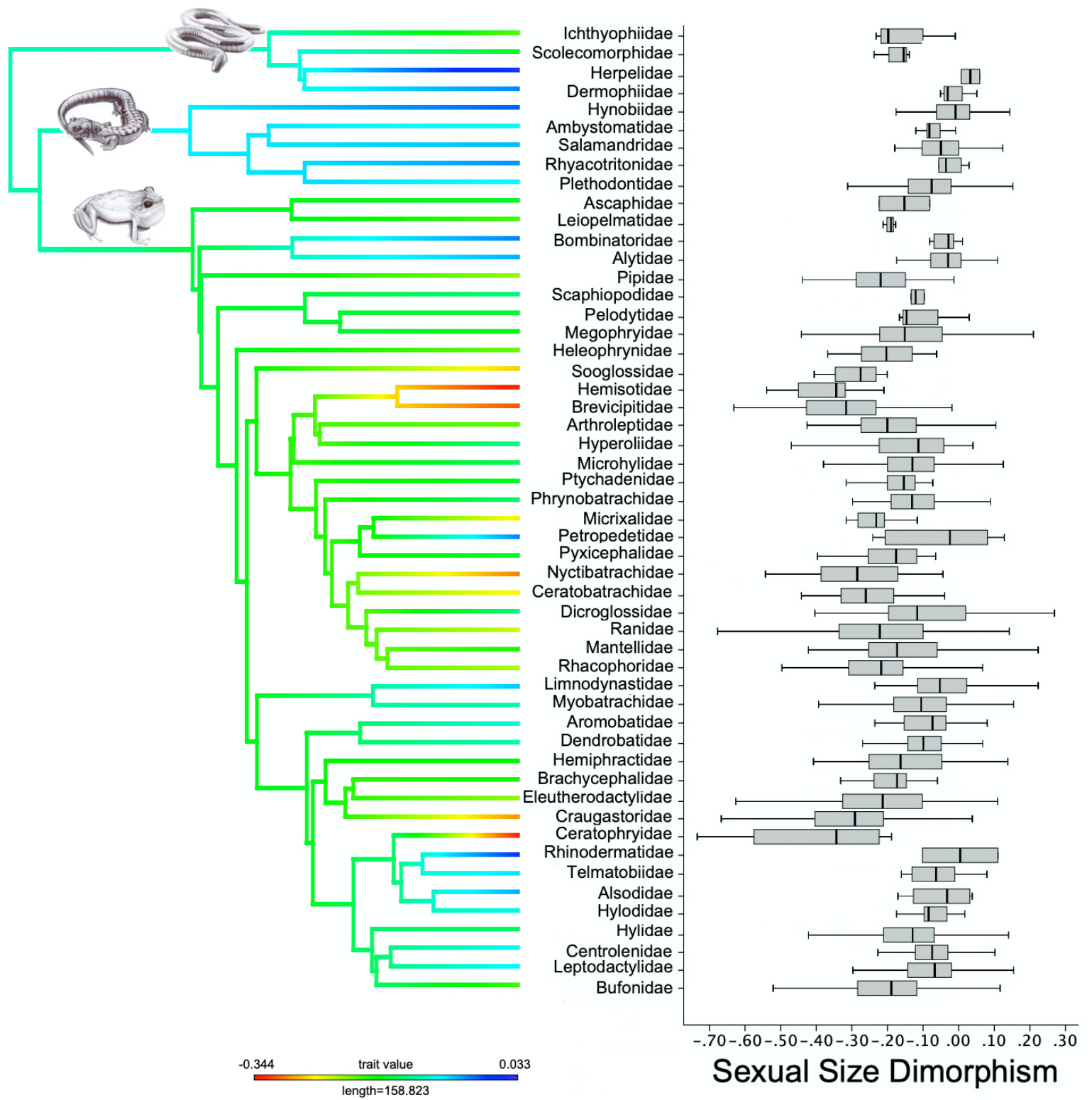


Figure 2. Patterns of sexual size dimorphism across orders of amphibians. The same tendencies for predominant female-biased SSD observed across families are observed when the frequency distribution (A; black vertical lines indicate sexual size monomorphism), and (taxonomic) order-level median (and quartile distribution) of SSD (B) are plotted. See methods for details about SSD calculations.

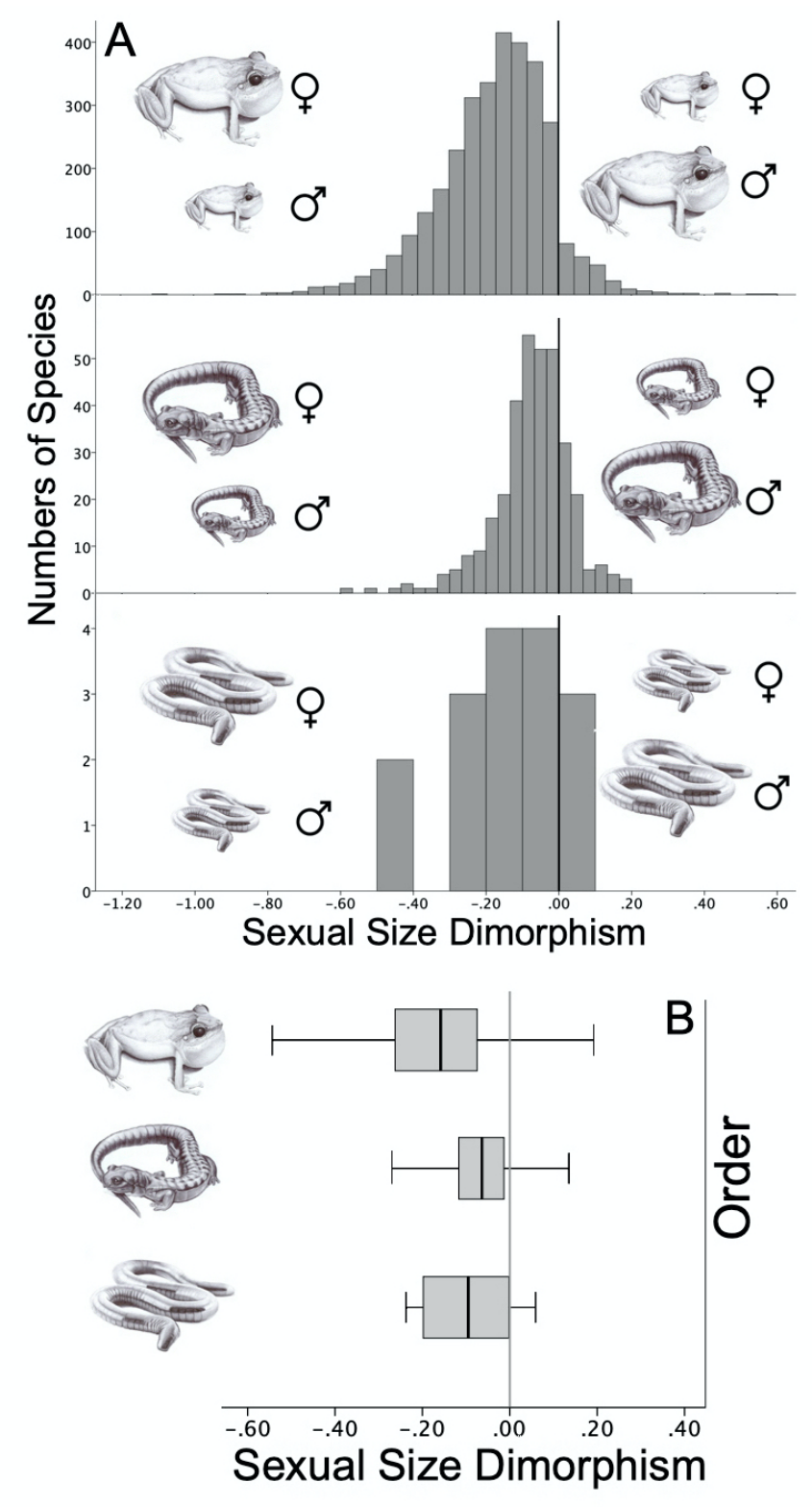


Figure 3. The relationships between transient fecundity (brood size) and (interspecific and intersexual) variation in body size. The analyses show that increasing clutch size in all three amphibian orders (anurans: gray, salamanders: red, and caecilians: blue) is a strong function of increasing female body size (A). The plot to the right $(B)$ shows the (lack of significant) relationships between fecundity and SSD for the same three groups (and colour codes).
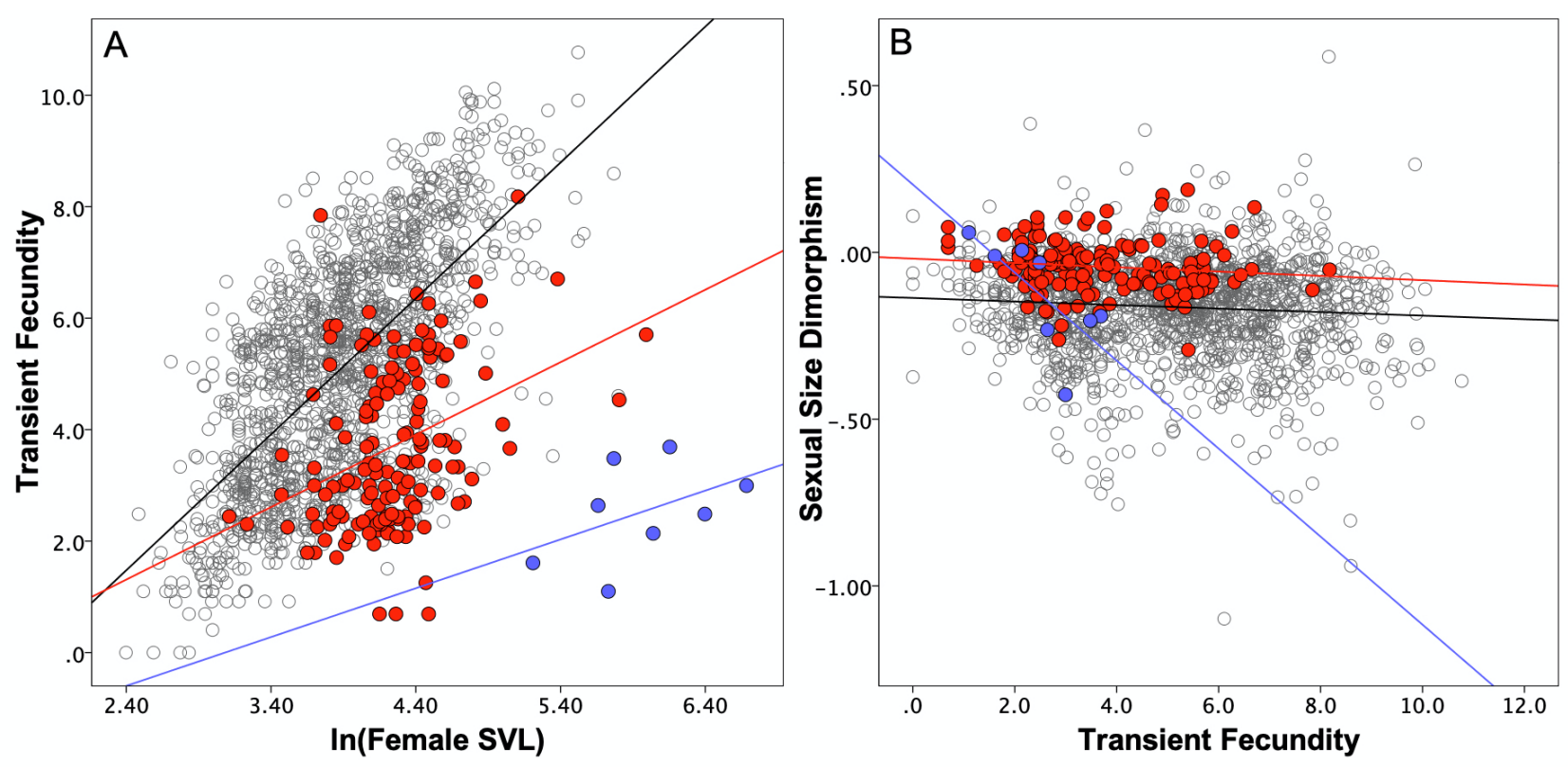
Figure 4. Effects of ecological pressures, but not sexual selection, on amphibian SSD. Frequency

distributions of SSD on the top plots (a-d) show that the frequency of anuran (a-b) and salamander (c-d) species with male-biased SSD (to the right of the black vertical line that indicates sexual size monomorphism) is not higher in species in which access to mates is mediated by male-male combats (a, c) relative to species in which no male combats exist (b, d). These findings are confirmed by the boxplots, which show that the magnitude of SSD is qualitatively identical for species with (M-MC) and without (NC) male-male combats in both anurans (e) and salamanders (f). Bar plots, in contrast, show the significant influence of microhabitat use (Aq: aquatic, SA: semi-aquatic, Ter: terrestrial, Fos: fossorial, Veg: bushes and trees) on the variation of SSD among salamanders (h), and the lack of significant effects in anurans (g). The opposite effects are observed for the relationship between SSD and nesting site (Aq: aquatic, Ter: terrestrial, Bur: burrows, Veg: bushes and trees, PB: parents' body), which has a significant influence in anurans (i), but not in salamanders (j). In these plots (g-j) SSD is treated as an absolute measure of the magnitude of SSD, regardless of whether females or males are the larger sex.

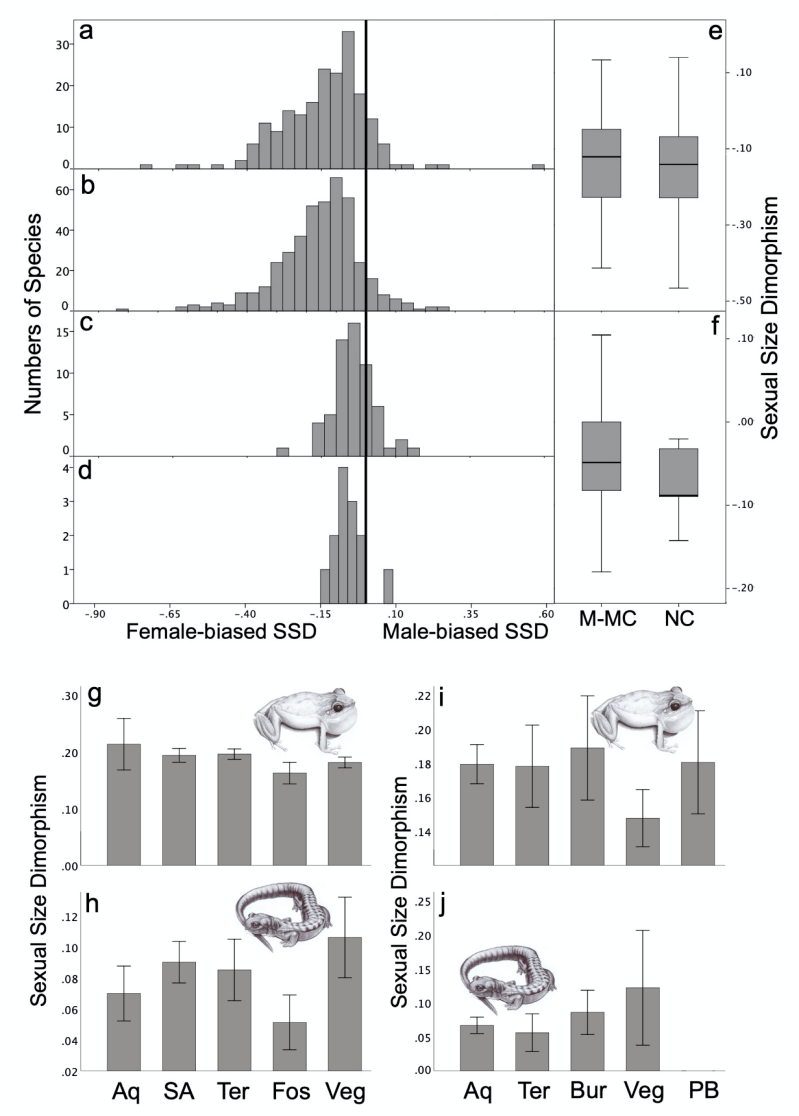


Figure 5. Global distribution of median SSD in amphibians. Maps show the distributional patterns of SSD separately for anurans (a) and salamanders (b), with grid cell sizes of $2 \times 2$ degrees. Hexagon density scatter plots showing the effects of thermal seasonality on the magnitude of SSD among grid-cells in anurans (c) and salamanders (d). The distributional patterns of SSD for caecilians are not shown given limited availability of data.

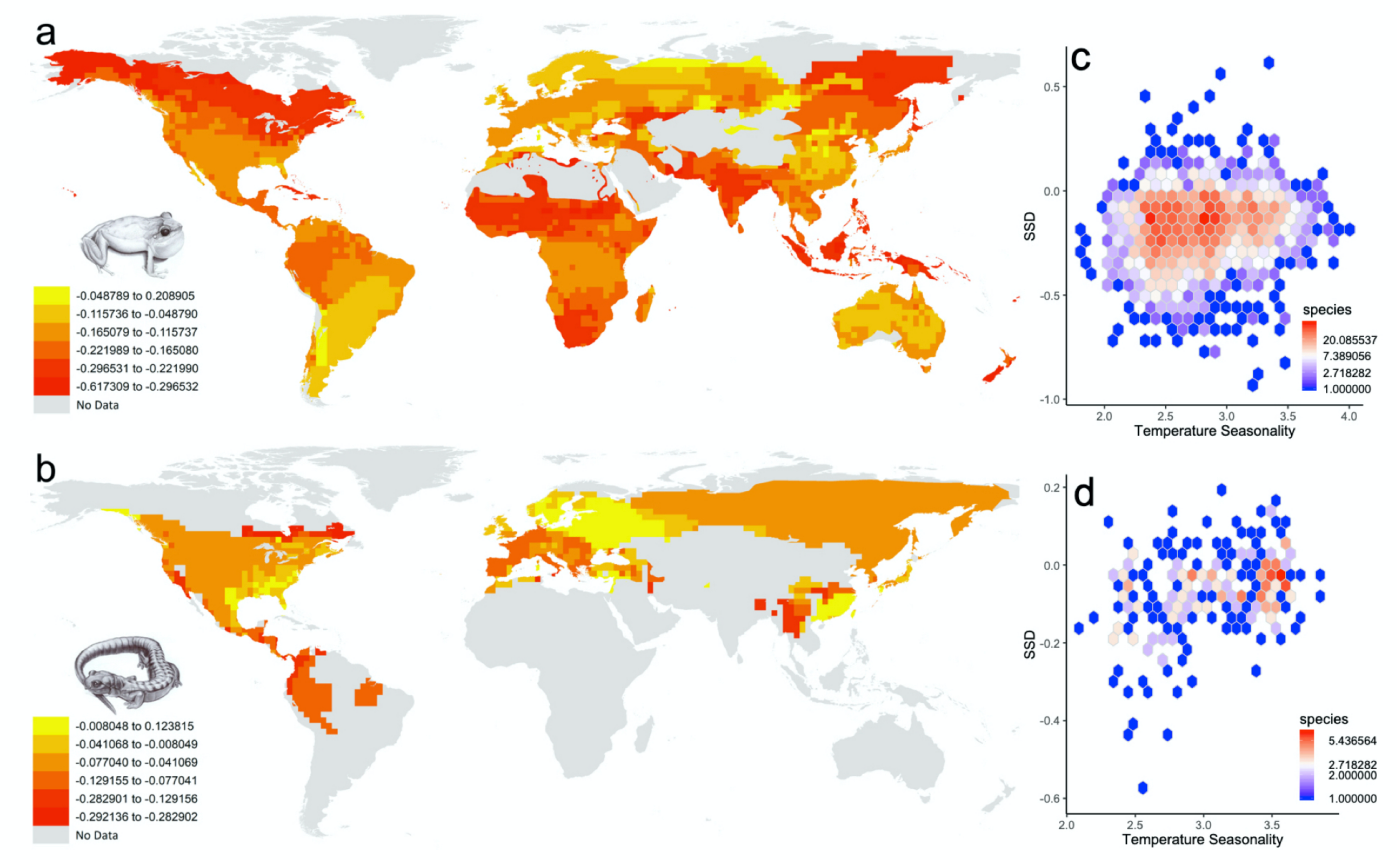

